\title{
BULLYING AND CYBERBULLYING IN THAILAND: A
}

\section{REVIEW}

\author{
Ruthaychonnee Sittichai \\ Prince of Songkla University \\ Faculty of Humanities and Social Sciences Muang, Pattani 94000 Thailand \\ ruthsittichai@gmail.com
}

Peter K Smith

Goldsmiths, University of London

New Cross, London SE14 6NW, England

pss01pks@gold.ac.uk

\begin{abstract}
Bullying is a severe problem, especially in schools, including the relatively new phenomenon of cyberbullying (via mobile phones and the internet). Research in Western countries suggests that over the last decade, cyberbullying accounts for about one-quarter to one-third of all bullying. Here we review research on cyberbullying, and bullying in general, in an eastern culture, Thailand. Eight relevant reports were found; however only three explicitly discussed cyberbullying. Reports were mainly quantitative, and did not consistently distinguish (cyber) bullying from general aggression. Suggestions are made for future research in this area, in Thailand and other Southeast Asian countries.
\end{abstract}

Keywords: Bullying, Cyberbullying, Thailand 


\section{INTRODUCTION}

The study of bullying, especially in schools, has a history of some three decades (Olweus, 1999; Smith, 2011). Bullying is usually defined as being an aggressive, intentional act or behavior that is carried out by a group or an individual, repeatedly and over time, against a victim who cannot easily defend him or herself (Olweus, 1999); it is based on an imbalance of power and can also be defined as a systematic abuse of power (Smith \& Sharp, 1994; Rigby, 2002). Thus, bullying is a subset of aggression, and one with particularly unpleasant consequences that raises issues of human rights (Greene, 2006).

The definitional criteria for bullying are important in carrying out research on the topic. Hunter, Boyle and Warden (2007) compared questionnaire responses by Scottish 8-13 year old pupils to items concerning both aggressive behaviors, and bullying behaviors (where there was a perceived imbalance of power through physical strength, group size, and/or social popularity). Their study showed that victims of bullying, as opposed to victims of peer aggression more generally, felt less control over the situation and were more depressed.

\section{The Advent of Cyberbullying}

Bullying is traditionally thought of as being physical, verbal, or relational (such as social exclusion), and direct (face-to-face) or indirect (such as rumor-spreading). However, in the last decade especially, a relatively new form of bullying has emerged through the use of modern communication technologies, often labeled as cyberbullying (Tokunaga, 2010; Smith, 2012).

Cyberbullying is carried out via mobile phones; instant messaging, e-mail, chat rooms or social networking sites such as Facebook and Twitter. Rivers and Noret (2010) have described the content of abusive text messages and e-mails, in an English sample, as including threats of physical violence, abusive or hate-related, name calling (including homophobia), death threats, ending of platonic relationship(s), sexual acts, demands/instructions, threats to damage existing relationships, threats to home/family, and menacing chain messages. Other acts of cyberbullying can include attempting to infect the victim's computer with a virus, and flooding an e-mail inbox with messages.

Bullying, including cyberbullying, can have severe negative effects on all concerned, but especially for victims. For the victims, these negative outcomes include lowered self-esteem, feelings of depression, and, in severe cases, suicidal ideation and even suicide (Kim \& Leventhal, 2008). The effects of being a victim of cyberbullying appear to be as 
severe as for traditional bullying, with some evidence of additive effects. Gradinger, Strohmeier and Spiel (2009) found that depressive symptoms were increased in victims of either kind of bullying, but was significantly greater for victims of both traditional and cyber bullying (poly-victims) than for victims of either form alone. Similarly, Brighi et al. (2012) found significantly poorer self-esteem and higher loneliness scores, in poly-victims compared to victims of traditional or cyber bullying alone.

There are important social consequences following from cyberbullying. Students have been suspended from school, in Canada for example, for cyberbullying classmates (Asunda, 2010), and in Ireland for cyberbullying teachers (Flynn, 2012). The legal implications of cyberbullying, and rights and responsibilities on the internet, are matters of contemporary debate (Miller, 2006; Gillespie, 2006; Vandebosch, Beirens, D'Haese, Wegge, \& Pabian, 2012).

\section{Issues in Studying Bullying and Cyberbullying in Different Cultures}

Most of the research on bullying and cyberbullying has been carried out in western countries. The recent Handbook of Bullying in Schools: An International Perspective (Jimerson, Swearer, \& Espelage, 2010), which has 41 chapters, has only 2 representing perspectives outside Europe, North America and Australia (1 comparative, 1 on Japan). Apart from a significant literature on the related phenomenon of ijime in Japan (Morita et al., 1999), and some on wang-ta in South Korea (Koo et al., 2008; Lee et al., 2011), there has been relatively little research in other non-western countries.

Prevalence rates internationally (for global bullying) vary from around 5\% to $44 \%$ for bullies (average around 21\%), 7\% to $43 \%$ for victims (average around $24 \%$ ), and $2 \%$ to $32 \%$ for bully-victims (average around 8\%) (Cook, Williams, Guerra \& Kim, 2010). For cyberbullying, rates are around one-quarter to one-third those of global bullying (Smith, 2012). Prevalence rates can be affected by many factors, including definition, sample characteristics, study location, year of study, informant source (pupil, teacher etc) and time referent period.

Cross-national comparisons of bullying in different countries can be important but raise several significant issues. Although many similarities emerge in cross-national studies of school bullying, there are also important differences (Smith \& Monks, 2008). Such differences may be actual differences in behavior, perhaps due to societal differences in dimensions such as individualism-collectivism, or hierarchy. More prosaically, they may be due to differences in schooling arrangements (age bands, lunchtime arrangements, 
extent of home-room class teaching). And, there are also differences in conceptions of abuse, and abuse of power; and differences in the words available to describe these. In addition, all of these factors can and do change through historical time, especially for cyberbullying, where types of technology, and penetration through the population, are changing and increasing at rapid but varying rates in different countries. Thus, the date of a study is an important variable, especially for cyberbullying.

One important issue relates to language. Many languages do not have a linguistic term that closely corresponds to the English term bullying. In the Latin languages, terms such as violenza or prepotenza (in Italian) have broader meanings the bullying, including aggressive acts without necessarily having repetition or imbalance of power (Smith et al., 2002). A second relates to actual behaviors. Although the phenomenon of bullying does appear to have some broad similarities across cultures, differences have been found between the forms it takes in western societies, and the more collectivist Pacific Rim societies of Japan and South Korea; with a notably greater peer group involvement and use of relational aggression in these latter countries (Morita et al., 1999; Koo et al., 2008).

\section{BULLYING AND CYBERBULLYING IN THAILAND}

Here we review the literature on bullying and cyberbullying in Thailand. The country may be considered more collectivist than the predominately individualistic cultures of Western Europe, North America, and Australasia; but it differs from Japan and South Korea in being less industrialized, and having a large Muslim and Buddhist population. Out of a population of over 65 million, some 26 percent have at least one (often more) mobile phone/s, 28 percent have easy internet/ICT access, and 16 percent are Facebook subscribers (statistics for March 31, 2011, from: http://www.internetworldstats.com/stats3.htm;

http://en.wikipedia.org/wiki/List_of_countries_by_number_of_mobile_phones_in_use; http://www.nationmaster.com/graph/med_mob_pho-media-mobile-phones). These statistics refer to the general population, and may be substantially higher for young people (cf. Songsiri \& Musikaphan, 2011).

There are several words similar to the English word bullying in the Thai language, although no one term is very similar. Smith et al. (2002) examined the meaning of three terms: nisai mai dee means bad habit, generally bad behavior; klang (klaēng) refers to more verbal behaviors, and tum raai (thamrāi) to more physical behaviors. Two other terms current nowadays are rang kae (rangkaē) which also means physical aggression, and kaow 
raow which means general aggression.

We found a limited number of studies on bullying and cyberbullying in Thailand. We searched for articles that included the word bullying or cyber bullying in the title, or one of the similar Thai words if the article was in Thai. We found seven studies plus one extended newspaper report. Here we review their findings. We then compare with international findings, and make some suggestions for future research on the topic in Thailand.

Laeheem, Kuning, McNeil, and Besag (2008) reported on bullying in primary schools in the Pattani district of Southern Thailand. A total of 1,440 students were interviewed, at 5 public schools and 2 private schools (one Islamic, one Chinese). Younger students were aged 7-10 years and older students 10-13 years. The date of the study is given as between November 2005 and March 2006. The researchers stated that "in this study we defined 'bullied' as a person's actions to cause physical or psychological harm on another person" (p.180), which in the wider literature would be taken as a definition of aggression, rather than of bullying. Students were asked if they had ever bullied anyone, in 16 different ways (physical and verbal, but not including cyber bullying). Students who said 'yes' to at least 2 out of the 16 categories were labeled as 'bullies'. Based on this criterion, 32.9\% of students reported that they had (ever) bullied other children. The classroom was the most frequent location. Bullying others was significantly associated with age (more frequent in older children), with having seen family physical abuse between their parents, and with preference for action (rather than comedy or mystery) cartoons. An association with gender (more frequent in boys) did not remain independently significant in a logistic regression analysis.

A report by Laeheem, Kuning, and McNeil (2009), appears to be based on the same sample of 1,440 students. A different (but not completely specified) dichotomizing of students into 'bullied others' and 'not bullied others' groups was carried out, with the 'bullied others' group now constituting $20.9 \%$ of the sample. Significant risk factors were now in public school (rather than private), boys, non-Muslim (rather than Muslim), 11 years or older (rather than 8 to 10 years), had witnessed parental physical abuse, and preferred action (to comedy or mystery) cartoons. The language used in the survey was not specified, but was presumably Thai, however, in these two studies, the word 'bully' was avoided by asking about harming someone or hurting their feelings. The estimates of bullying prevalence $-32.9 \%$ in one report and $20.9 \%$ in the other - are high compared to many studies; this is probably because of the long time referent period ('have you ever ...'), and because their definition describes aggressive behaviors generally rather than bullying 
specifically.

A somewhat similar study by Yodprang, Kuning, and McNeil (2009) reported on physical bullying among lower secondary school students in the Pattani province. This survey was conducted with 244 students aged 12 to 19 years, and was carried out in December 2006. The number of schools sampled is not specified. The procedure appears similar to the study on primary school students; however it only asked about five types of physically aggressive behavior, both as perpetrator and victim, on a yes/no basis. Questions referred to behavior during both the preceding six months and during the previous month. On these criteria, the overall prevalence of physical bullying was reported as $18.5 \%$ (both during the last six months and the last month). Physically bullying others was not significantly associated with gender, but was associated with age (older children), ethnicity (Thai compared to Malay or Chinese), school type (urban rather than rural) and parental violence (witnessing physical violence between parents). The findings regarding parental violence (also found for primary school students) are in line with much other literature. The prevalence rate of $18.5 \%$ is probably inflated because their definition describes physically aggressive behaviors generally rather than physical bullying specifically. The lack of gender difference is unusual, in that almost all studies find physical aggression and bullying to be more common in boys.

Tapanya (2006) reported a survey on bullying behavior with 3,047 students (1,532 girls and 1,515 boys from grades 4 to 9 , i.e. 10 to 15 years) and 1,300 teachers ( 961 female, 338 male) in 2006. The sample was from all over Thailand. The Revised Olweus Bully/Victim questionnaire (1996) was used for the students and the ISPCAN Parent Questionnaire: Punishment, Discipline and Violence in the Home, for the teachers. The pupils were only asked about being bullied. For all forms of bullying, boys were bullied more than girls, especially in the lower grades (grades 4 or 5). Most of the victims reported the bully to their friends (56\%) followed by their parents (37\%), teachers $(32 \%)$, and siblings (29\%). Further methodological details, including the date of the survey, are not available.

A more recent study about bullying was conducted by a medical doctor, Buttabote (2011). This study was about the relationship between bullying behavior and self-esteem in Attention-Deficit/Hyperactivity Disorder (ADHD) patients. The sample group was 102 ADHD patients aged between 10-18 years old who were being treated at the Child and Adolescent Psychiatric Outpatient Unit of Ramathibodi Hospital from December 2009 to April 2010. Data was collected by self-report questionnaires, which consisted of Thai 
versions of the Olweus Bully/Victim questionnaire (no cyberbullying questions) and the Rosenberg self-esteem scale. The analysis distinguished four roles: bully-only, victim-only, bully-victim, and not involved. The proportion of ADHD patients who exhibited or were victims of some bullying behaviors was $53 \%$, most of them being in the bully-victim group. Victims of bullying most frequently reported being made fun of or teased in a hurtful way, while those who bullied others most frequently reported behaviors of hitting, kicking, pushing, and placing someone under arrest. The self-esteem score for the victim-only group and bully-victim groups were statistically significantly lower than for the not involved group. The findings suggested that self-esteem is related to bullying behavior in ADHD patients especially for those being victimized.

Of the five studies reviewed so far, it is noticeable that none measured cyber bullying. It is possible that cyber bullying would be picked up by a global question (such as 'how often have you bullied someone in the last term?'), but the first three studies explicitly asked about physical and verbal behaviors (not cyber), while the latter two used an earlier version of the Olweus questionnaire without items on cyber (or electronic) bullying, which recent versions of the questionnaire include. This is unfortunate, as cyber bullying has been noticeable in many countries from at least 2002 onwards (Noret \& Rivers, 2010), and the surveys reviewed were carried out between 2005 and 2010; also although penetration of ICT use in Thailand is not as high as in most western countries, it is still substantial at around $26-28 \%$ in the general population (see above).

However, three studies have produced direct evidence regarding cyberbullying in Thailand. A report on cyberbullying by Boonoon (2009), in the online news paper 'The Nation', discussed findings from a survey conducted in August 2009 by the Wisdom Society for Public Opinion Research of Thailand, a private organization concerned about the welfare of Thai children. This report cited cyberbullying as a situation when a child or teenager is repeatedly tormented, threatened, harassed, humiliated, embarrassed or otherwise targeted by another child or teenager using text messaging, e-mail, instant messaging or any other type of digital technology. The survey involved 2,500 students around the country, aged 12 to 24 years; 970 were vocational students and 1,530 were general students. Further methodological details about the survey are not given. It was found that $43 \%$ of students had been threatened over the Internet. Most of them, studying at high school, declined to disclose details, but said they had been annoyed by the cyberbullying and particularly by attempts to lure them into offline meetings. Few parents or teachers were told of bullying episodes. 
One suggestion arising from the survey was that children from "divorced or violated" families were seeking, via the Internet, to impose on others the same harassment, embarrassment and threats that they felt in their lives. Boonoon argues that victims of cyber bullying are being affected psychologically, and that parents should seek to understand their children, become closer to them, but also monitor their children's ICT behavior and learn information-technology skills. A better understanding of the technology would allow all concerned to reduce online harassment and pursue criminal charges against perpetrators. The report also argues that the Thai government should educate both parents and students to help them understand the problem and "leverage the soul and emotions of students"; meanwhile, an organization should be set up to work together with the private sector to solve the problem before cyberbullying becomes an even bigger social problem (Boonoon, 2009).

Musikaphan (2009) provided comparative data on cyberbullying in Thailand, and Japan. Data collection was carried out in Thailand with 2,000 students for a quantitative study, and 14 key informants for qualitative purposes; and in Japan with 100 students for quantitative study and $12 \mathrm{key}$ informants for qualitative purposes. The age range of the students was not stated. The quantitative surveys included measures of incidence, and attitudes to cyberbullying. From the quantitative surveys, it was found that nearly 59\% of respondents had been cyberbullied more than once per month, while in Japan, reported cases of cyber bullying were very low in frequency, with more than half of respondents saying that they have never faced or received information about cyber-bullying. In terms of attitudes toward cyberbullying, in Thailand, $60 \%$ of students believed that cyberbullying was "negatively avoidable behavior" which should be prohibited, but some $35 \%$ believed that cyberbullying might be an "acceptable behavior"; whereas in Japan, 68\% thought that it was "bad" behavior. These quantitative findings suggest that cyberbullying may be more prevalent in Thailand than in Japan (despite high ICT penetration in Japan, see also Aoyama, Utsumi and Hasegawa, 2012), and also that attitudes to cyberbullying may be less negative. Findings from the qualitative aspect of the research suggested differences between the two countries in culture and philosophy of living which may lead to different aspects of cyberbullying, and to ways for problem reaction and policy implementation concerning it.

Finally, Songsiri and Musikaphan (2011) reported findings from 1,200 pupils aged mostly 14-16 years, from 21 schools in Bangkok. The date of the survey is not reported. For this sample, ICT penetration was very high; $96 \%$ owned a mobile phone, and $95 \%$ used 
the internet. Seven types of cyberbullying were reported: electronic messages with angry and vulgar language; repeatedly sending nasty, mean and insulting messages; talking someone into revealing secrets or embarrassing information, then sharing it online; sending or posting gossip or rumors about a person to damage his or her reputation or friendships; pretending to be someone else and sending or posting material to get that person in trouble or danger or to damage that person's reputation or friendships; repeated intense harassment and denigration including threats; and intentionally and cruelly excluding someone from an online group. Of these, the first two were the most frequent. However their frequency measures are difficult to interpret, as they included both experiencing these yourself, or hearing about it occurring to their friends; in addition, no definition of cyberbullying is given. Duration of internet use and aspects of family relationships (exposure to violence; family income) were found to relate to the cyberbullying measure, but no details of these findings are presented.

\section{DISCUSSION}

These several studies mark the beginnings of investigation of bullying and cyberbullying phenomena in Thailand. Apart from one aspect of Musikaphan (2009), all are quantitative studies, and some use versions of western instruments, such as the Olweus Bully/Victim questionnaire. It is clear that bullying-like behaviors are not infrequent in Thailand. Some findings - such as victims being more likely to have low self-esteem, and bullies more likely to have witnessed domestic violence - are very much in line with studies in other countries.

However it is largely unexamined whether the nature and forms of bullying-like phenomena in Thailand (and indeed other south-east Asian countries) are really very similar to those in western countries, or whether they might be more similar to phenomena in the Pacific Rim countries of Japan and South Korea. To ascertain this might require some different approaches. One would be to start from a more qualitative approach, to find out the range of bullying-like phenomena in a country, rather than using pre-determined categories identical to those in western instruments, such as the Olweus Bully/Victim questionnaire. Another would be to use the same instrument in two or more countries (preferably after initial qualitative work, to ensure that the instrument is suitable in both cultures) and to compare findings, especially on some categories found to be useful previously, such as ratio of bullies to victims, whether bullies are in the same class as victims, relative importance of social exclusion as a type of bullying. Previous 
comparisons between Japan and England, and in South Korea, suggest these are important constructs to look at (Kanetsuna \& Smith, 2002; Kanetsuna, Smith, \& Morita, 2006; Koo et al., 2008; Lee, Smith \& Monks, 2011). The one study that compares findings in Thailand and Japan (Musikaphan, 2009) gives insufficient methodological detail, and has a very small Japanese sample.

Particularly regrettable is the absence of studies on cyberbullying, with only three out of eight studies in the last six years including this form of bullying (and some explicitly if unwittingly excluding it). The evidence from the one comparative study is that cyberbullying in Thailand is a serious issue, and more so than in Japan (Musikaphan, 2009).

Some studies do not give the date of the survey; but things change, and cyberbullying especially is changing rapidly. Also, larger-scale interventions may change the situation in a country. For these reasons, giving the date of a survey is an important aspect to report.

Most studies do not specify the language of the survey. But when questions are asked about bullying or cyberbullying, the equivalent term in the language needs to be specified and it's equivalence to bullying discussed. With the exception of 3 terms in Thai (see Smith et al., 2002), no proper study has been made of the equivalence of such terms to bullying. On the other hand if no 'bullying' term is used, it needs to be very clear that the distinguishing criteria of 'repetition' and 'imbalance of power' are being taken account of. If they are not, then it is questionable whether bullying or cyberbullying is being measured. Some studies had a very lax criterion for 'bullying', and were measuring 'aggressive behaviors' and not bullying.

Given the seriousness of the cyberbullying problem in Thailand, from the limited evidence available so far, there is a strong case for a more focused research program on the topic. Such a study should include both qualitative and quantitative components. It should distinguish (cyber) bullying from more general aggression, specify full methodological details (time reference point, date of study, linguistic terms used, etc), and include a sufficiently large and representative sample that some generalizations can be made on a national basis. Prevention efforts on bullying and cyberbullying are gathering pace internationally (Spiel, Salmivalli \& Smith, 2011; Hinduja \& Patchin, 2012), and a more informed knowledge base for Thailand can assist in the use and modification of such programs to help young people in Thailand experiencing, or involved in, bullying and cyberbullying. 


\section{REFERENCES}

Aoyama, I., Utsumi, S., \& Hasegawa, M. (2012). Cyberbullying in Japan: Cases, government reports, adolescent relational aggression and parental monitoring roles. In Q. Li, D. Cross, and P.K. Smith (Eds.), Cyberbullying in the global playground: Research from international perspectives (pp.183-201). Chichester: Wiley-Blackwell. http://dx.doi.org/10.1002/9781119954484.ch9.

Asunda, P.A. (2010). 28 students suspended for cyber bullying. Curriculum Review, 49(7), 3.

Boonoon, J. (2010, December 2). Cyber bullying problem for Thai kids. The Nation.

Brighi, A., Melotti, G., Guarini, A., Genta, M.L., Ortega, R., Mora- Merchán, J.A., Smith, P.K., \& Thompson, F. (2012). Self-esteem and loneliness in relation to cyberbullying in three European countries. In Q. Li, D. Cross, and P.K. Smith (Eds.), Cyberbullying in the global playground: Research from international perspectives (pp.32-56).

Chichester:

Wiley-Blackwell. http://dx.doi.org/10.1002/9781119954484.ch3.

Buttabote, P. (2011). The relationship between bullying behavior and self-esteem in attention deficit / hyperactivity disorder patients. Journal of Psychiatric Association Thailand, 56(2), 93-102. [in Thai: abstract in English]

Cook, C.R., Williams, K.R., Guerra, N.G., \& Kim, T.E. (2010). Variability in the prevalence of bullying and victimization: A cross-national and methodological analysis. In S.R. Jimerson, S.M. Swearer, and D.L. Espelage (Eds.), Handbook of bullying in schools: An international perspective (pp. 347-362). New York \& London: Routledge.

Flynn, S. (2012, April 9). Department under pressure over cyber-bullying of teachers. The Irish Times.

Gillespie, A.A. (2006). Cyber-bullying and harassment of teenagers: The legal response. Journal of Social Welfare \& Family Law, 28(2), 123-136. http://dx.doi.org/10.1080/09649060600973772.

Gradinger, P., Strohmeier, D., \& Spiel, C. (2009). Traditional bullying and cyberbullying. Zeitschrift für Psychologie/Journal of Psychology, 217(4), 205-213. http://dx.doi.org/10.1027/0044-3409.217.4.205.

Greene, M.B. (2006). Bullying in schools: A plea for a measure of human rights. Journal of Social Issues, 62(1), 63-79. http://dx.doi.org/10.1111/j.1540-4560.2006.00439.x. 
Hinduja, S., \& Patchin, J.W. (2012). School climate 2.0: Preventing cyberbullying and sexting one classroom at a time. Thousand Oaks, CA: Sage Publications.

Hunter, S.C., Boyle, J.M.E., \& Warden, D. (2007). Perceptions and correlates of peer victimization and bullying. British Journal of Educational Psychology, 77(4), 797-810. http://dx.doi.org/10.1348/000709906X171046.

Jimerson, S.R., Swearer, S.M., \& Espelage, D.L. (2010). Handbook of bullying in schools: An international perspective. New York \& London: Routledge.

Kanetsuna, T., \& Smith, P.K. (2002). Pupil insights into bullying, and coping with bullying: A bi-national study in Japan and England. Journal of School Violence, 1(3), 5-29. http://dx.doi.org/10.1300/J202v01n03_02.

Kanetsuna, T., Smith, P.K., \& Morita, Y. (2006). Coping with bullying at school: children's recommended strategies and attitudes to school-based interventions in England and Japan. Aggressive Behavior, 32(6), 570-580. http://dx.doi.org/10.1002/ab.20156.

Kim, Y-S., \& Leventhal, B. (2008). Bullying and suicide: A review. International Journal of Adolescent Mental Health, 20(2), 133-154. http://dx.doi.org/10.1515/IJAMH.2008.20.2.133.

Koo, H., Kwak, K., \& Smith, P.K. (2008). Victimization in Korean schools: The nature, incidence and distinctive features of Korean bullying or wang-ta. Journal of School Violence, 7(4), 119-139. http://dx.doi.org/10.1080/15388220801974084.

Laeheem, K., Kuning, M., McNeil, N. \& Besag, V.E. (2008). Bullying in Pattani primary schools in Southern Thailand. Child: care, health and development, 35, 178-183. http://dx.doi.org/10.1111/j.1365-2214.2008.00890.x

Laeheem, K., Kuning, M., \& McNeil, N. (2009). Bullying: Risk factors becoming 'bullies'. Asian Social Science, 5(5), 50-57.

Lee, S-H., Smith, P.K., \& Monks, C.P. (2011). Perceptions of bullying-like phenomena in South Korea: a qualitative approach from a lifespan perspective. Journal of Aggression, Conflict and Peace Research, 3(4), 210-221. http://dx.doi.org/10.1108/17596591111187738.

Miller, C. (2006). Cyber stalking bullying. Law Enforcement Technology, 33(4), 18-25.

Morita, Y., Smith, P.K., Junger-Tas, J., Olweus, D., Catalano, R., \& Slee, P. (1999). Sekai no ijime. Tokyo: Kaneko Shobou.

Musikaphan, W. (2009). A study of cyber-bullying in the context of Thailand and Japan. Nakhon Pathom: National Institute for Child and Family Development, Mahidol 
University, Thailand.

Olweus, D., Sweden. (1999). Sweden. In P. K. Smith, Y. Morita, J. Junger-Tas, D. Olweus, R. Catalano, and P. Slee (Eds.), The nature of school bullying: A cross-national perspective (pp. 7-27). London: Routledge.

Rigby, K. (2002). New perspectives on bullying. London: Jessica Kingsley.

Rivers, I., \& Noret, N. (2009). 'I h8 u': findings from a five-year study of text and email bullying. British Educational Research Journal, 36(4), 643-671. http://dx.doi.org/10.1080/01411920903071918.

Smith, P.K. (2011). Bullying in schools: thirty years of research. In C. Monks and I. Coyne (Eds.), Bullying in different contexts (pp.36-60). Cambridge: Cambridge University Press. http://dx.doi.org/10.1017/CBO9780511921018.003.

Smith, P.K. (2012). Cyberbullying and cyber aggression. In S.R. Jimerson, A.B. Nickerson, M.J. Mayer, and M.J. Furlong (Eds.), Handbook of school violence and school safety: International research and practice (pp.93-103). New York, NY: Routledge.

Smith, P.K., \& Monks, C.P. (2008). Concepts of bullying: Developmental and cultural aspects. International Journal of Adolescent Medicine and Health, 20(2), 101-112. http://dx.doi.org/10.1515/IJAMH.2008.20.2.101.

Smith, P.K., Cowie, H., Olafsson, R., \& Liefooghe, A.P.D., in collaboration with 17 additional authors (2002). Definitions of bullying: a comparison of terms used, and age and sex differences, in a 14-country international comparison. Child Development, 73(4), 1119-1133. http://dx.doi.org/10.1111/1467-8624.00461.

Smith, P. K., \& Sharp, S. (1994). School bullying: Insights and perspectives. London: Routledge. http://dx.doi.org/10.4324/9780203425497.

Songsiri, N., \& Musikaphan, W. (2011). Cyber-bullying among secondary and vocational students in Bangkok. Journal of Population and Social Studies, 19(2), 235-242.

Spiel, C., Salmivalli, C., \& Smith, P.K. (2011).Translational research: National strategies for violence prevention in school. International Journal of Behavioral Development, 35(5), 381-382. http://dx.doi.org/10.1177/0165025411407556.

Tapanya, S. (2006). A survey of bullying among students. Chiangmai: Psychiatric Department, Faculty of Medicine, Chiangmai University.

Tokunaga, R.S. (2010). Following you home from school: A critical review and synthesis of research on cyberbullying victimization. Computers in Human Behavior, 26(3), 277-287. http://dx.doi.org/10.1016/j.chb.2009.11.014. 
Vandebosch, H., Beirens, L., D’Haese, W., Wegge, D., \& Pabian, S. (2012). Police actions with regard to cyberbullying: The Belgian case. Psicothema, 24(4), 646-652.

Yodprang, B., Kuning, M., \& McNeil, N. (2009). Bullying among lower secondary school students in Pattani Province, Southern Thailand. Asian Social Science, 5(4), 46-52. 